\title{
CURRÍCULOS E CURRICULARIZAÇÃO DA FORMAÇÃO DOCENTE CONTEMPORÂNEA NOS MESTRADOS EM EDUCAÇÃO DA UFPA, UEPA, UFT NA/DA AMAZÔNIA BRASILEIRA
}

\author{
Damião Rochal \\ Marcos Irondes Coelho2
}

\section{RESUMO}

A curricularização da formação inicial docente, no ensino, na pesquisa e na extensão, nos mestrados em educação são questões das quais nos ocupamos e refletimos neste trabalho. A produção textual resulta da Pesquisa Documental de aspectos dos currículos dos cursos de mestrados em educação da UFPA, UEPA, UFT; três universidades públicas da região Norte, na Amazônia brasileira. Fazemos, também Análise Qualitativa Interpretacionista, conforme as três etapas metódicas inter-relacionadas: a etapa investigativa, uma interpretativa e outra propositiva. Nossa fundamentação teórica é de autores da área de currículo e formação de professores tais como: Bernard Charlot (2000), Jurjo Santomé (1998), Gimeno Sacristán (2000), Ivani fazenda $(2001,2008)$, Elizabeth Macedo (2001), Tomaz Tadeu Silva (2000). A curricularização da extensão na educação superior para a formação inicial, está prescrita na legislação; na pós-graduação ainda não está definida, mas, poderá vir a ser exigida já que a legislação sobre a extensão para a educação superior aponta para o processo de curricularização também na especialização, no mestrado, doutorado. Os cursos de mestrado em educação da UFPA, UEPA, UFT, criados antes do marco legal da extensão acadêmica, não explicitam nos seus currículos a curricularização da extensão, apesar de, curricularizadas estarem, o ensino e a pesquisa.

Palavras-chave: Currículo. Curricularização. Formação docente contemporânea.

\section{CURRICULUMS AND CURRICULARIZATION OF CONTEMPORARY TEACHING TRAINING IN MASTERS IN EDUCATION OF UFPA, UEPA, UFT IN/OF THE BRAZILIAN} AMAZON

\footnotetext{
1 Pós-Doc. pela UEPA. Doutor em educação pela UFBA. Mestre em educação pela UFG. Docente do PGEDA/UFPA e do PPGE/UFT. Líder do grupo de pesquisa CNPQ Gepce/Minorias. Sócio da Anped/Nacional GT 12 - Currículo e Anped/Norte. Coordenador do PPPGE/UFT. Brasil. ORCID: https://orcid.org/0000-0002-5788-7517. E-mail: damiao@uft.edu.br

2 Doutorando em Educação na Amazônia e Mestre em Educação, pela UFT. Vice-Líder do grupo de pesquisa CNPQ Gepce/Minorias. Professor da Educação Básica da Secretaria da Educação do Tocantins. ORCID: https://orcid.org/0000-0003-3428-9714. E-mail: marcos.irondes@gmail.com
} 


\section{ABSTRACT}

The curriculum of initial teacher training, in teaching, research and extension, in master's degrees in education are issues that we are concerned with and reflected in this work. The textual production results from the Documentary Research of aspects of the curricula of the Masters in Education courses at UFPA, UEPA, UFT; three public universities in the North region, in the Brazilian Amazon. We also do Qualitative Interpretationist Analysis, according to the three interrelated methodical stages: the investigative stage, one interpretive and the other propositional. Our theoretical foundation is from authors in the area of curriculum and teacher training such as: Bernard Charlot (2000), Jurjo Santomé (1998), Gimeno Sacristán (2000), Ivani Fazenda (2001, 2008), Elizabeth Macedo (2001), Tomaz Tadeu Silva (2000). The curriculum of extension in higher education for initial training is prescribed by law; in postgraduate studies it is not yet defined, but it may be required since the legislation on extension to higher education points to the curricularization process also in specialization, in master's, doctorate. The master's courses in education at UFPA, UEPA, UFT, created before the legal framework of academic extension, do not explain in their curricula the curriculum of the extension, although they are curricular, teaching and research.

Keywords: Curriculum."Curricularização". Contemporary teacher training.

\section{CURRICULOS Y CURRICULARIZACION DE LA FORMACION DOCENTE CONTEMPORANEA EN MASTERES EN EDUCACION DE UFPA, UEPA, UFT EN/DE LA}

\section{AMAZONIA BRASILEÑA}

\section{RESUMEN}

El currículo de la formación inicial del profesorado, en docencia, investigación y extensión, en los másteres en educación son temas que nos preocupan y reflejan en este trabajo. La producción textual es el resultado de la Investigación Documental de aspectos de los planes de estudio de los cursos de Maestría en Educación en UFPA, UEPA, UFT; tres universidades públicas de la región norte, en la Amazonía brasileña. También hacemos Análisis Interpretacionista Cualitativo, de acuerdo con las tres etapas metódicas interrelacionadas: la etapa investigativa, una interpretativa y la otra proposicional. Nuestro fundamento teórico es de autores en el área de currículo y formación docente como: Bernard Charlot (2000), Jurjo Santomé (1998), Gimeno Sacristán (2000), Ivani Fazenda (2001, 2008), Elizabeth Macedo (2001), Tomaz Tadeu Silva (2000). El plan de estudios de extensión en la educación superior para la formación inicial está prescrito por la ley; en estudios de posgrado aún no está definido, pero puede ser requerido ya que la legislación sobre extensión a la educación superior apunta al proceso de curricularización también en especialización, maestría, doctorado. Los cursos de maestría en educación de la UFPA, UEPA, UFT, creados antes del marco legal de la extensión académica, no explican en sus planes de estudio el currículo de la extensión, aunque sí son curriculares, docentes e investigativos.

Palabras clave: Plan de estudios. "Curricularização". Formación docente contemporánea. 


\section{INTRODUZINDO A QUESTÃO SOBRE "CURRICULARIZAR"}

Curricularizar é tornar um conteúdo curricular, é creditar, atribuir cargahorária e créditos, é tornar uma atividade numa proposta formativo pedagógica. Significa inserir nos currículos, atividades formativas que cumpram vários objetivos a partir da inserção do aluno em contextos do cotidiano social, mesmo que se considere que toda ação acadêmica é pedagógica e passível de valoração e avaliação, e que todo currículo é abrangente, dinâmico e existencial, é "curriculum vitae".

A curricularização se refere a todas as situações que se vivencia dentro e fora da Universidade. Portanto, curricularizar é reconhecer e valorizar as experiências vividas pelos alunos, com objetivos formativos, sob a orientação ou não da Instituição.

A discussão da "curricularização" está prevista no Plano Nacional de Educação (PNE) de 2014, e foi regulamentada pelo Conselho Nacional de Educação (CNE) em 2018, ao estabelecer Diretrizes para a Extensão na Educação Superior Brasileira, por meio de atividades extensionistas nas modalidades de programas, projetos, cursos e oficinas, eventos e prestação de serviços, tornando a "extensão" processo acadêmico na formação discente; mas o início dessa discussão é bem anterior.

No seio da luta pela redemocratização e reconstrução das instituições políticas e sociais, foi reelaborada a concepção de Universidade Pública, redefinidas as práticas de Ensino, Pesquisa e Extensão e questionada a visão assistencialista das ações extensionistas. A partir de então, a Extensão Universitária passou a ser percebida como um processo que articula 0 Ensino e a Pesquisa e se relaciona com os novos movimentos sociais. Embora ainda restrita à dimensão processual, a busca da institucionalização da Extensão tornou-se o principal desafio. O entendimento era de que essa institucionalização deveria envolver toda a Universidade Pública.

O reconhecimento legal das atividades extensionistas e a criação do Fórum Nacional de Pró-Reitores de Extensão das Universidades Públicas Brasileiras (FORPROEX, 1987), atualmente Fórum de Pró-Reitores de Extensão das Instituições Públicas de Educação Superior Brasileiras, em novembro de 1987, são marcos importantes, na medida em que propiciaram à comunidade acadêmica as condições para redefinir a Extensão Universitária. No I Encontro Nacional de Pró-Reitores 
de Extensão das Universidades Públicas Brasileiras, um novo conceito foi pactuado (FORPROEX, 2012, p. 14).

Vejamos que o novo conceito de "extensão universitária", a partir do Fórum Nacional de Pró-Reitores de Extensão das Universidades Públicas Brasileiras, tornou-a processo educativo, cultural e científico, articulando o ensino e a pesquisa de forma indissociável.

Apesar das diretrizes do CNE para a extensão na educação superior proporem "a articulação entre as atividades de extensão e as atividades de ensino e pesquisa realizadas nas instituições de ensino superior", entendemos que a curricularização está prevista, pelo menos, desde 2013, nas Diretrizes Curriculares Nacionais Gerais para a Educação Básica (DCNG/EB), ao definirem currículo como "conjunto de valores e práticas que proporcionam a produção e a socialização de significados no espaço social" e que contribuem, intensamente, para "a construção de identidades sociais e culturais" dos alunos. E ao assegurarem, que "a organização do tempo curricular deve ser construída em função das peculiaridades de seu meio e das características próprias" dos seus alunos, "não se restringindo às aulas das várias disciplinas". E mais, que o "percurso formativo" (destaque nosso) deve ser "aberto e contextualizado, incluindo não só os componentes curriculares centrais obrigatórios", mas também, "outros componentes flexíveis e variáveis que possibilitem percursos formativos que atendam aos inúmeros interesses, necessidades e características" dos alunos.

Na educação superior a discussão da "curricularização" perpassa pelo debate sobre a "indissociabilidade".

O preceito constitucional de indissociabilidade entre Ensino, Pesquisa e Extensão e os institutos consagrados à Extensão Universitária na LDB e no PNE 2001-2010 denotam sua institucionalização no âmbito formal. Por seu caráter vinculatório, essas iniciativas representam a consolidação de uma etapa decisiva na construção da política de Extensão Universitária. Mas ainda há muito a ser feito para o fortalecimento dessa política, em termos de sua implantação e implementação.

$[\ldots]$ 
A conjuntura atual, em geral favorável à expansão e consolidação da Extensão Universitária, é também desafiadora, na medida em que suscita expectativas de criação de paradigmas contrahegemônicos que primam pelo espírito colaborativo (FORPROEX, 2012, p. 37).

Neste sentido da institucionalização da "extensão universitária", podemos conceber a "curricularização" em qualquer "proposta pedagógica", em qualquer "percurso formativo" em qualquer "currículo", independentemente da carga-horária atribuída para a "acreditação curricular".

Lembremos que a regulamentação da curricularização, mesmo em meio às muitas discordâncias e resistências das associações, entidades, fóruns, está, atualmente, associada à "BNCC", que foi colocada como a referência obrigatória para os "currículos diversos" da educação básica e para a formação inicial de professores; além da "Parte Comum", que compõem os currículos de todas as etapas e modalidades da "Educação Básica". E desde a Resolução $n^{\circ} 2$, de $1^{\circ}$ de julho de 2015, que define as Diretrizes Curriculares Nacionais para a Formação Inicial de Professores em nível Superior, cursos de Licenciatura, cursos de Formação Pedagógica para graduados e cursos de Segunda Licenciatura, as "atividades de extensão" estão postas como açõa importante para o exercício da docência.

\section{ASPECTOS CURRICULARES DOS CURSOS DE MESTRADOS}

A região Norte possui 16 programas de pós-graduação em educação. Selecionamos três programas neste estudo, pelas relações docentes, pedagógicas e de pesquisas que temos construído ao longo da última década dos anos 2000, com estes programas e nestas universidades, e com seus pesquisadores.

Importante registrar que quando se observa a questão de pessoal qualificado na Amazônia, independente da área de educação, o Programa Nacional de Pós-Graduação (PNPG), apresenta como sendo este um dos desafios da ciência na/da Amazônia, e revela que: 
A carência de pessoal qualificado, se não é a razão principal dos desafios, [...] contribui para esses continuem incluídos de forma substantiva entre os grandes entraves para o desenvolvimento sustentável da Amazônia. Há na região 11 Universidades Federais, quatro Universidades Estaduais, uma Instituição municipal, três Institututos de Pesquisas federais e mais de uma centena de escolas privadas de ensino superior. Juntas, estas instituições têm em seus quadros pouco mais de quatro mil doutores, parte dos quais não está mais envolvida com a pesquisa e não contribui com a formação de pessoal em nível de pós-graduação.

Esses últimos anos marcaram, portanto, uma fase de expansão do quadro de doutores na Amazônia e, consequentemente, do número de programas de pós-graduação [...]. Da mesma forma, a organização desse pessoal em grupos de pesquisa evoluiu de maneira susbstancial e possibilitou 0 aperfeiçoamento das ações em Ciência, Tecnologia e Educação (PNPG, 2010, p. 10-11).

É desafiador na região Norte a ampliação do número de doutores nas instituições de ensino e pesquisa.

Em meio as discussões de instituicionalização da "extensão universitária" observamos o processo de "acreditação curricular" dos três programas, por nós pesquisados, nesse trabalho. A Análise Qualitativa Interpretacionista, se deu em três etapas metódicas inter-relacionadas: a etapa investigativa, realizada nas páginas on-line dos programas, para apreendermos conceitos e concepções; uma interpretativa, à luz das discussões sobre formação e currículo, para entendermos a curricularização com base nos autores citados e com os quais dialogamos; e outra propositiva, que resultou na escrita do texto, como relatório de pesquisa interfaceado de narrativas da revisão teórica e de nossas análises argumentativas.

Passamos a tratar de aspectos curriculares dos programas da UFPA, UEPA E UFT.

O currículo do curso de mestrado da UFPA é pautado pelos "princípios da interdisciplinaridade, flexibilidade e integração ensino-pesquisa", e busca entender a educação "a partir de seus múltiplos determinantes, nexos e 
contradições, e a explorar as interligações entre as diferentes áreas do campo da educação e desta com as ciências afins" (PPGED/UFPA, 2020).

A implantação do curso de Mestrado em Educação: Políticas Públicas da UFPA se dá em 1993. O curso apresentou proposta de curso novo: Mestrado Acadêmico em Educação, com aprovação em 2003. A partir do conceito 4, em 2008, aprovou também o Doutorado.

Um dos objetivos do Programa é "possibilitar espaços formativos capazes de estimular, constituir e fortalecer acúmulos teórico-práticos em torno do fenômeno educativo" (PPGED/UFPA, 2020).

O mestrado é composto de 28 créditos, 450 horas, distribuídos entre disciplinas obrigatórias e atividades. As disciplinas obrigatórias são constituídas de duas disciplinas do curso: uma disciplina obrigatória de Linha e uma disciplina optativa. As disciplinas obrigatórias de curso são: "Pesquisa em Educação" e "Educação Brasileira", além da disciplina "Seminário de Pesquisa". As atividades são produções acadêmicas a serem publicadas pelo aluno, além da Dissertação (PPGED/UFPA, 2020).

O Programa de Pós-Graduação em Educação PPGED/UEPA, em sua proposta "apresenta a educação em sua dimensão mais ampla e complexa, propondo-se o desafio de pensar a especificidade da Amazônia Paraense sob variados contextos socioculturais e políticos" (PPGED/UEPA, 2020).

O PPGED/UEPA iniciou suas atividades em 2005, com um colegiado constituído por 20 docentes, com sede em Belém, capital do Estado do Pará. Justifica sua proposta de educação para esta região, a partir de seus sujeitos que se "caracterizam enquanto sujeitos de uma sociabilidade única em seus matizes de floresta, de águas e habitando um espaço caracterizado pelo isolamento em função das enormes distâncias", e reconhece que esta realidade "dificulta sua conexão ao sistema educacional formal" (PPGED/UEPA, 2020). Todavia, afirma que estes habitantes "são guardiães de saberes ancestrais de raízes e matizes afro-indígenas que devem ser estudados e preservados como demarcadores identitários importantes dos 
povos indígenas, remanescentes de quilombos e ribeirinhos" (PPGED/UEPA, 2020).

Conforme sua proposta curricular a finalidade básica do programa da UEPA é "O aprofundamento teórico-metodológico das questões epistemológicas, que envolvem o campo educacional e a ênfase no desenvolvimento da pesquisa" (PPGED/UEPA, 2020). Possui 5 blocos de disciplinas e atividades: as disciplinas fundamentais, que são obrigatórias; as disciplinas eletivas; o seminário de pesquisa; a orientação de dissertação e as atividades programadas. O aluno deverá cumprir 26 créditos e uma carga horária total de 520 horas.

Para os alunos do PPGED/UEPA as atividades programadas do currículo deverão propiciarem a realização de "estudos diversificados sobre o tema investigado, em outros Programas e Instituições, de acordo com seus planos de estudos", além da participação em "Cursos e Seminários e a apresentação de trabalhos em eventos" (PPGED/UEPA, 2020).

Já o Programa de Educação PPGE/UFT obteve aprovação da sua APCN junto à Capes e foi implantado em 2012, se constituindo como o primeiro Programa de Pós-Graduação em Educação da Universidade.

Atualmente o programa da UFT não possui disciplinas obrigatórias, dentre as suas 10 disciplinas. Sua integralização depende do curso dos 24 créditos e a totalidade de 360 horas, incluindo a defesa e aprovação de Dissertação (PPGE/UFT, 2020).

Suas pesquisas são desenvolvidas conforme suas duas linhas de pesquisa: "Currículo, formação de professores e saberes docentes" e "Estado, sociedade e práticas educativas" (PPGE/UFT, 2020).

No geral os programas em tela têm uma "trajetória curricular" obrigatória com disciplinas e atividades, todavia se baseiam em cumprimento de créditos, comumente de 15 horas cada crédito. Não se identifica a "curricularização" como proposto na extensão para as atividades extensionistas nas modalidades de programas, projetos, cursos e oficinas, eventos e prestação de serviços. Todavia, todas as disciplinas cursadas pelos alunos somam e contam créditos para integralização dos 
programas, o que para nós constitui "curricularizar" a formação, no sentido ampliado do termo.

\section{CURRICULARIZAÇÃO DA FORMAÇÃO DOCENTE CONTEMPORÂNEA}

A curricularização da formação docente perpassa pelo entendimento do "o como" os "componentes curriculares obrigatórios", as "atividades optativas ou seletivas" ou as "experiências sócio-culturais-educacionais" estão definidas e creditadas no "currículo oficial prescritivo" de um curso. É compreender como o "ensino", a "pesquisa" e a "extensão" estão distribuídas na "organização do tempo curricular" e no "percurso formativo" de uma dada proposta de currículo, seja numa etapa/modalidade da educação básica ou num curso de graduação, ou num curso de especialização, ou ainda num curso de mestrado ou doutorado.

Claro que na curricularização das atividades acadêmicas de extensão dos cursos de graduação, na forma de componentes curriculares, conforme a Resolução $n^{\circ}$ 7, de 18 de dezembro de 2018, está assegurada no mínimo, $10 \%$ (dez por cento) do total da carga horária curricular estudantil dos cursos de graduação, como parte da matriz curricular dos cursos.

A mesma legislação, afirma que as Diretrizes para a Extensão na Educação Superior Brasileira, também podem ser direcionadas aos cursos superiores de pós-graduação, conforme o Projeto Político Pedagógico (PPP) da instituição de educação superior, com o prazo de até 3 (três) anos, a contar da data da homologação. Portanto, o prazo para as instituições se adequarem as novas regras se extinguem em 18 de dezembro de 2021 (BRASIL, 2018). Ou seja, a "curricularização" da extensão no Mestrado e Doutorado está posta.

Nessa discussão é importante notarmos que a "indissociabilidade" das três dimensões da Universidade, o "ensino", a "pesquisa" e a "extensão", prevista no artigo 207 da Constituição Federal de 1988, e suas relações internas com a sociedade, sempre estiveram em debates, e em busca de definição e regulamentação, apesar da "autonomia acadêmica", e dos debates nos seus diversos fóruns (FORGRAD, FOPROP, FORPROEXT). 
Entretanto, nos parece que existe uma "dissociabilidade" em relação à "extensão". Vejamos que:

[...] O tripé ensino-pesquisa-extensão é desequilibrado em várias

universidades brasileiras, especialmente em relação ao eixo extensão, em decorrência de pelo menos dois aspectos: a) reduzido reconhecimento de mérito às atividades extensionistas, que, em geral, são vistas institucionalmente como atividades menores "nobres" da tríade; b) desconhecimento do que é extensão universitária pelos próprios extensionistas, já que muitos dos programas, projetos e ações são voltados prioritariamente para o público interno, quando o público externo à Universidade deveria, por definição, ser o foco. Outro aspecto decorrente desse desconhecimento é o fato de que muitas ações extensionistas sejam pautadas pela simples transmissão de conhecimento, quando a relação deveria ser dialógica com a comunidade (PAIVA, 2018, p. 23).

A partir desse pressuposto, lembramos que, pelo menos ao que se refere à carga-horária, "curricularizar" requer que a proposta, desenvolvimento e conclusão da curricularização, estejam devidamente registrados, documentados e analisados, de forma que seja possível organizar os planos de trabalho, as metodologias, os instrumentos e os conhecimentos gerados; que precisam ser sistematizadas e acompanhadas, com o adequado assentamento, além de registradas, fomentadas e avaliadas por instâncias administrativas institucionais, devidamente estabelecidas, em regimento próprio; e que também, devem ser adequadamente registradas na documentação dos estudantes como forma de seu reconhecimento formativo.

Em relação a "extensão" nos cursos superiores de pós-graduação da UFPA, UEPA, UFT não se identifica qualquer menção a essa curricularização, até porque o marco regulatório para o campo da extensão é recente, precisamente de 2018. No entanto, no que se refere ao "ensino" e a "pesquisa" a curricularização é evidente.

Pensamos que a discussão sobre "curricularização" perpassa pelas contradições do contemporâneo que nos desafia pelo seu caráter 
extremado de mudanças, por desestabilizar as certezas, por meio da provoc (ação) nos modos de pensar e agir. A crise, os impasses, as incertezas dos tempos de agora resultam, em geral, da confrontação crítica das contradições e limites de alguns dos princípios e ideais do século XX, reflexos da revolução francesa: liberdade, igualdade, fraternidade.

\begin{abstract}
Afinal, mais do que nunca estamos nos dando conta de que a promessa moderna de conseguirmos administrar, programar e controlar efetivamente o devir - o que levou o pensamento moderno a reduzir o devir ao futuro - não se cumpriu e não poderá se cumprir. Diante dessa descoberta, abriram-se as duas alternativas mais conhecidas: ou 0 nilismo ou a presentificação. Como bem sabemos, para contornar a primeira (ou fugir dela), a contemporaneidade está tratando de trazer, cada vez mais intensa e aceleradamente, o devir para o presente ou, nas palavras de Paul Klee, descontar o futuro no presente. Se por um lado fica extremamente difícil, senão impossível, compatibilizar niilismo com educação, muitos optam pela presentificação, sem se darem conta de que assumi-la significa comprometer o próprio sentido temporal atribuído à educação (VEIGA-NETO, 2008, s/p).
\end{abstract}

O contemporâneo pensado como tempo histórico é o período específico atual da história do mundo ocidental, iniciado a partir da Revolução Francesa. "Numa outra acepção diz-se que contemporâneo refere-se a "coetâneo", aquele que viveu ou existiu na mesma época, ou ainda, que se constitui de acontecimentos recentes". Tempo atual. "É a experimentação crítica nos interstícios dos acontecimentos" (ROCHA, 2013, p. 122- 123).

Trabalhamos neste texto com a concepção do contemporâneo como atualidade, como o friso que dobra o que se passa em torno de nós e o que acontece em nós.

\title{
CURRICULARIZAR CURRÍCULOS CONTEMPORÂNEOS É INTEGRÁ-LOS
}

Por plural que seja o termo "currículo", trabalhamos aqui com uma noção simples: currículo como um conjunto de conteúdos, vivências e práticas a serem ensinados e (re)aprendidos, segundo a organização escolar 
e/ou acadêmica; portanto, ainda estamos a falar de "currículo disciplinar". A perspectiva é que, ao abordá-lo assim, se chegue ao seu entendimento rizomático e não-disciplinar, com outras possibilidades curriculares, pois ainda somos disciplinarizados.

\begin{abstract}
Nossa experiência corrente dá-se com o currículo disciplinar, isto é, um modelo de currículo em que os conteúdos a serem dispostos para a aprendizagem apresentam-se na forma de disciplinas, áreas de saber tomadas de forma autônoma, independente e estanque. Toda a pedagogia e a escola modernas (isto é, desde o século dezessete) assentam-se sobre uma noção disciplinar de currículo. No entanto, a disciplina e o currículo disciplinar são muito mais antigos, apesar de não receberem ainda tal denominação (GALLO, 2004, p. 38).
\end{abstract}

Da modernidade aos dias atuais, tematizou-se sobre o currículo. Essa tematização levou os estudos curriculares a se consolidarem como campo de estudos e pesquisas. Comumente fazemos três perguntas orientadoras da trajetória do desenvolvimento curricular ao longo de sua história: como se faz um currículo? O que um currículo faz com as pessoas? Como as pessoas fazem o currículo?

A contemporaneidade colocou em xeque o (des)conforto das práticas comuns do "currículo disciplinar". Estamos vislumbrando o início da experiência curricular de níveis diversos de integração, que vão do multidisciplinar ao transdisciplinar. "Integrar interdisciplinarmente é integrar em profundidade, largura e síntese" (FAZENDA, 2001, p.142).

Evitando os dualismos e as narrativas fatalistas, buscamos uma reflexão baseada na "intercrítica" (MACEDO, 2007), uma crítica da crítica, numa perspectiva de estudo. Tendência que, na pesquisa em educação, tem sido considerada significativa. Intercrítica ou hipercrítica "[...] implica reconhecer o caráter intrinsecamente discursivo e representacional dos sentidos que conferimos àquilo que consideramos serem os problemas do mundo e até mesmo a realidade do mundo" (VEIGA-NETO, 2008, s/p).

Em sua pluralidade currículo é "documento", "texto", "narrativa", "discurso", "forja nossa identidade" (SILVA, 2000), "[...] modela-se dentro de 
um sistema concreto, dirige-se a determinados professores e alunos, serve-se de determinados meios, cristaliza, enfim, num contexto, que é o que acaba por the dar o significado real" (SACRISTÁN, 2000, p. 21).

Por não trabalharmos com um sentido restritivo de currículo, apresentamos mais sentidos de currículo, em busca de outros sentidos, seja na escola ou na Universidade, pois:

Os currículos são a expressão do equilíbrio de interesses e forças que gravitam sobre o sistema educativo num dado momento, enquanto através deles se realizam os fins da educação no ensino escolarizado.

$[\ldots]$

Todas as dificuldades que se atribuem e são destinadas implícita ou explicitamente à instituição escolar, de socialização, de formação, de segregação ou de integração social, etc., acabam necessariamente tendo um reflexo nos objetivos que orientam todo o currículo, na seleção de componentes do mesmo, desembocam numa divisão especialmente ponderada entre diferentes parcelas curriculares e nas próprias atividades metodológicas às quais dá lugar. Por isso, o interesse pelos problemas relacionados com o currículo não é senão uma consequência da consciência de que é por meio dele que se realizam basicamente as funções da escola como instituição.

[...] O valor da escola se manifesta fundamentalmente pelo que faz ao desenvolver um determinado currículo, independentemente de qualquer retórica e declaração grandiloquente de finalidades. Nessa mesma medida, o currículo é um elemento nuclear de referência para analisar o que a escola é de fato como instituição cultural e na hora de elaborar um projeto alternativo de instituição (SACRISTÁN, 2000, p. 17-18).

Atualmente, ainda é comum as organizações curriculares basearem-se no modelo linear disciplinar, modelo de currículo baseado no desenvolvimento da ciência do século XVII ao século XX. De acordo com esse modelo, entendia-se que a compartimentação e a especialização possibilitariam o progresso acelerado de cada área do saber. O conhecimento disciplinar assim, "[...] refere-se a um conjunto de estruturas abstratas e a leis intrínsecas que permitem classificações particulares de conceitos, problemas, dados e procedimentos de verificação de acordo com modelos de coerência assumidos" (SANTOMÉ, 1998, p. 103). 
Em razão disso, "[...] a disciplinarização pedagógica nada mais é que um reflexo, uma continuidade, uma decorrência da disciplinarização epistemológica" (GALLO, 2001, p. 168). A partir desse pressuposto entende-se o sentido de disciplina como "componente curricular" tão presente em nossos currículos. E o que é uma disciplina?

Uma disciplina é uma maneira de organizar e delimitar um território de trabalho, de concentrar a pesquisa e as experiências dentro de um determinado ângulo de visão. Daí que cada disciplina nos oferece uma imagem particular da realidade, isto é, daquela parte que entra no ângulo de seu objetivo (SANTOMÉ, 1998, p. 55).

Mesmo nos programas de pós-graduação, ainda somos, disciplinares e disciplinadores. O movimento de "integração curricular" não se constitui ainda em uma "mudança curricular substantiva" nos modelos e nas práticas pedagógicas. Estamos falando da possibilidade de integração de currículos, uma vez que, mesmo atingindo o nível máximo de integração, continuamos no formato de currículo disciplinar. E nesse sentido, curricularizamos o itinerário formativo dos acadêmicos nos programas, mas não integramos os currículos. E mais, mesmo que consigamos algum nível de integração curricular, ainda assim, continuamos nos currículos disciplinares, pelo simples fato de que:

Um currículo interdisciplinar, pluridisciplinar, transdisciplinar etc. continua a ser, antes de tudo, um currículo disciplinar. E embora aparentemente essas ações em princípio pareçam significar um avanço pedagógico importante, temo que sua ação seja bastante perniciosa, pois, dando a ilusão de que superam os problemas do currículo disciplinar, garantem sua continuidade. Penso que se trata, na verdade, de ousarmos pensar a possibilidade de currículos não disciplinares (GALLO, 2001, p.174).

A partir desse pressuposto, a curricularização no Mestrado e Doutorado, será significativa, quando construirmos "currículos nãodisciplinares". A busca por minimizar a "influência epistemológica e didática" da disciplinaridade passa pelo entendimento do que se constitui o "currículo disciplinar" (MACEDO, 2001). A crítica à fragmentação do conhecimento 
especializado, na ciência contemporânea, vem sendo construída por várias perspectivas. As análises dos processos de "disciplinarização do saber", seja escolar ou acadêmico, indicam que estes são resultantes da disciplinarização do campo científico:

Isso acontece na medida em que as disciplinas escolares são interpretadas como disciplinas científicas adaptadas para fins de ensino. Assim sendo, o grau e a forma de especialização das disciplinas no campo científico são utilizados como princípios de interpretação do contexto escolar, sem considerar os processos de recontextualização do conhecimento escolar (LOPES, 2001, p. 148-149).

A crítica da "interdisciplinaridade" sobre a "disciplinarização científica" chegou às disciplinas escolares e ao "currículo disciplinar". A disciplinaridade "[...] favorece mais a propagação de uma cultura da "objetividade" e da neutralidade, entre outras razões, porque é mais difícil entrar em discussões e verificações com outras disciplinas com campos similares ou com parcelas comuns de estudo" (SANTOMÉ, 1998, p. 109):

[...] a disciplinaridade, em princípio inquestionável, passou a ser questionada. Primeiro, no âmbito epistemológico. Se a especialização deu conta, em um primeiro momento, de responder aos problemas humanos e à sede de saber científico, em fins do século dezenove e no início do século vinte ela começa a apresentar desgastes e foi com a mais antiga das ciências modernas, a Física, que os desgastes começaram a aparecer. No interior de uma ciência baseada na perfeição do universo, na precisão das medidas e na certeza das previsões, apareceram os princípios da indeterminação, da incerteza, da relatividade (GALLO, 2001, p. 171).

O debate é complexo e necessário, quando refletimos sobre currículos, mesmo que, diferenciando-se "interdisciplinaridade" de "integração", as críticas à disciplinarização têm contribuído para o surgimento de outras possibilidades de elaboração de currículo: os "currículos integrados". Uma vez que a "interdisciplinaridade" se refere "[...] à inter-relação de diferentes campos de conhecimento com finalidades de pesquisa ou de solução de problemas" (SANTOMÉ, 1998, p. 112). Já o termo "integração", por sua vez, 
"[...] significa a unidade de partes, que seriam transformadas de alguma maneira" (SANTOMÉ, 1998, p. 112).

Pensamos que o que deveria constituir os currículos dos mestrados e doutorados em educação, é a "integração curricular". Mas não nos referimos apenas àqueles da nossa investigação dos aspectos curriculares das propostas dos programas da UFPA, UEPA, UFT.

Estamos defendendo então a argumentação, de que dependendo do nível de integração das disciplinas ou áreas, poderemos distinguir a "multidisciplinaridade" da "pluridisciplinaridade" e esta da "interdisciplinaridade" ou da "transdisciplinaridade" curriculares. Nessa acepção, a "multidisciplinaridade" representa o primeiro nível de integração das disciplinas, seguida da pluridisciplinaridade, da interdisciplinaridade até atingir a transdisciplinaridade.

O termo "transdisciplinaridade" surge por volta de 1997 nos congressos da Organização das Nações Unidas para a Educação, a Ciência e a Cultura (UNESCO). Conceitualmente, "trans" significa está ao mesmo tempo "entre" as disciplinas, "através" das diferentes disciplinas e "além" de toda disciplina, visando ao entendimento da realidade. Além do âmbito das disciplinas, a análise guattariana da transdisciplinaridade se preocupa com o "coeficiente de transversalidade" do indivíduo. Nesse sentido, significa entendermos,

[...] o grau de abertura de um indivíduo ou grupo para levar em conta essas múltiplas dimensões que atravessam e produzem suas vidas e subjetividades, no sentido de viverem o risco de se confrontar com o novo e a alteridade, assumirem o sentido de sua práxis e se instaurarem como indivíduos e grupos sujeitos, e não grupos sujeitados. Daí a exigência inevitável da "transdisciplinaridade", como estratégia de abordagem dos diversos componentes transversais que atravessam qualquer realidade humana e social (VASCONCELOS, 2007, p. 66).

Imaginamos sem entrar no mérito, nesse texto, o que constitui então um projeto de formação em rede, senão o "grau de abertura de cada docente em tornar-se e tornar o seu "fazer didático e pedagógico" em ato de currículo "transdisciplinar". Um desafio, uma vez que a compreensão do 
trabalho interdisciplinar perpassa por uma "ordenação científica" e uma "ordenação social" (FAZENDA, 2008), pois os "saberes disciplinares", em sua busca de cientificidade disciplinar, requerem que cada disciplina seja:

[...] analisada não apenas no lugar que ocupa ou ocuparia na grade, mas nos saberes que contemplam, nos conceitos enunciados e no movimento que esses saberes engendram, próprios de seu lócus de cientificidade. Essa cientificidade, então originada das disciplinas, ganha status de interdisciplina no momento em que obriga o professor a rever suas práticas e a redescobrir seus talentos, no momento em que ao movimento da disciplina seu próprio movimento for incorporado (FAZENDA, 2008, p.18).

Existem sentidos diversos para "interdisciplinaridade". Pode-se falar, conforme Fazenda (2008), de interdisciplinaridade escolar, curricular, pedagógica ou didática. Para cada uma das categorias da interdisciplinaridade, existem finalidades e objetivos específicos. Há particularidades e historicidade nesses conceitos. "Interdisciplinaridade escolar não pode confundir-se com interdisciplinaridade científica" (FAZENDA, 2008, p. 21). A nível de currículo, por exemplo, exige-se que:

[...] o estabelecimento de ligações de interdependência, de convergência e de complementaridade entre as diferentes matérias escolares que formam o percurso de uma ordem de ensino ministrado, a fim de permitir que surja do currículo escolar - ou de the fornecer - uma estrutura interdisciplinar (MOREIRA JOSÉ, 2008, p. 86).

A "interdisciplinaridade" como ação, além do sentido de integração das disciplinas, é uma exigência da contemporaneidade. Constitui-se como nova atitude diante do ato de conhecer.

\section{CONSIDERAÇÕES IN(CONCLUSIVAS): precisaremos reaver!}

Precisaremos de muita discussão e reflexão sobre a "curricularização da extensão" da/na pós-graduação em educação, mas, na nossa perspectiva, de "currículo integrado", "transdisciplinar" ou "currículos nãodisciplinares". 
Nesse sentido estamos argumentando que as bases conceituais do "currículo contemporâneo" e da formação, perpassam pelos "campos nãodisciplinares", e suscitam o entendimento da vivência com qualidade referenciada socialmente na presentividade, nos tempos de agora; porque ainda estamos concentrados entorno do "currículo disciplinar".

O "currículo centrado na matéria" e transmitido nas aulas magistrais, por exemplo, tem posto o conhecimento social de forma paralela ao conhecimento acadêmico. Consequentemente, cria-se a ilusão que as categorias de conhecimento trabalhadas são verdades inquestionáveis, quando, na realidade representam apenas uma possível via de entendimento entre tantas outras: "[...] o conhecimento aparece como um fim a-histórico, como algo dotado de autonomia e vida próprias, à margem das pessoas" (SANTOMÉ, 1998, p. 106). E mais, o "currículo centrado na matéria", perpassa a ideia de que nem todos os alunos têm condições de serem bem-sucedidos em algumas disciplinas, legitimando-se o próprio fracasso acadêmico. São, portanto, relegadas as contradições e refutadas as dimensões conflituosas da realidade social, como se assim fosse possível sua ocultação.

São comumente conhecidos, no modelo "curricular disciplinar", aqueles professores que excelentes em suas disciplinas e preocupados somente com suas matérias, consideram-se mais importantes do que outros, e até induzem os alunos a acreditarem e se interessarem por sua disciplina, em detrimento das disciplinas de outros professores. Esses docentes acreditam, ainda, que existem "matérias fáceis" e "matérias difíceis", "matérias obrigatórias" mais importantes do que aquelas "matérias optativas e seletivas". Nesse sentido podemos pensar o que são e representam os "componentes curriculares "obrigatórios" de um programa, de uma linha de pesquisa, e porque outros não se constituem assim. Será que ainda existem conteúdos "coisificados" (SILVA,1998), nos currículos dos programas de pósgraduação em educação? Ou será que ainda existem conteúdos como os "únicos possíveis" e "únicos pensáveis"? (SILVA, 1998). 
A partir desse pressuposto, o "currículo disciplinar", representado pela imagem de árvore, concebe as pessoas como seres fragmentados: os galhos da árvore "[...] vão se ramificando e se especializando cada vez mais, perdendo contato, pois cada ramo autonomiza-se em relação aos demais, embora permaneçam todos parte da mesma árvore" (GALLO, 2004, p. 44). Na perspectiva de rizoma, "[...] as coisas se passam de maneira distinta. Sua imagem remete para uma miríade de linhas que se engalfinham, como num novelo de lã emaranhado pela brincadeira do gato" (GALLO, 2004, p. 45) e possibilita-nos, uma filosofia do currículo.

Estamos com isso afirmando que no "currículo disciplinar" é possível o trabalho isolado, o eu-sozinho e incomunicável; contrariamente, na opção de organização do "currículo interdisciplinar" se cria "colegiados de saberes" e "ilhas de conhecimentos", potencializadores da formação de "arquipélagos de vivências e itinerâncias participativas" (DUTRA; DAMAS; ROCHA, 2009).

Um "currículo transdisciplinar", nesse sentido, trabalha com "as sínteses possíveis, com as relações possíveis, porque contextuais, históricas e políticas, sínteses estas requeridas pelas problemáticas humanas e seus desafios" (MACEDO, 2007, p. 55).

A formação contemporânea baseada na relação pedagógica hierárquica professor versus aluno, que habituou a todos nós, na condição de alunos, independente do nível de escolaridade, a "assistir aulas", de forma passiva e dependente da explicação oral, impacta negativamente a perspectiva de "trabalho autoral", "colaborativo" e "autônomo" (ROCHA; SOARES FILHO, 2019), e agora mediado por tecnologias ciberculturais, nos deixa impacatados no momento de trabalharmos sem a presencialidade, nestes momentos de crise sanitária e de afastamento físico dos anos de 2020.

A aprendizagem on-line, diante de uma "tela em branco" de um computador exige um usuário ativo. Todavia, a pouca experiência educacional de participação e produção se coloca como dificuldade de se atingir os objetivos do trabalho interativo, ou o que vimos chamando de "mobile learning" (MIRANDA; ROCHA, 2020). 
Por isso, se faz necessário pensarmos "interdisciplinarmente", pois esse pensar é mais abrangente que a soma de partes ou objetos distintos, constituindo-se em uma das alternativas de superação do modelo curricular disciplinar.

O que se quer na elaboração didático-pedagógico-curricular de cursos e itinerários formativos, em especial, nos mestrados e doutorados em educação, são propostas baseadas na "interdisciplinaridade", ou melhor ainda, em "campos não-disciplinares", pois assim, acreditamos ser possível a "curricularização" para além da "acreditação".

A construção de uma "matriz de currículo", entendida de forma "colaborativa e não-linear", conduzirá a arquiteturas de formação, com possibilidades de abertura não-determinista, e perseguirá os eixos da flexibilidade e da mobilidade acadêmica. Nesse ponto de vista, a matriz de currículo é referenciada e justificada pela ação e interação dos seus construtores. Não tem nem início nem fim, essa matriz tem "[...] fronteiras e pontos de interseção ou focos. Quanto mais rico o currículo, mais haverá pontos de intersecção, conexões construídas, e mais profundo será o seu significado" (DOLL JR., 1997, p. 178).

Curricularmente falando "currículos não-disciplinares", implementamse por intermédio do trabalho coletivo e solidário, em que o planejamento participativo reconhece como parte importante deste fazer, o princípio da "auto-organização", para pensarmos, por exemplo, com a ideia de "complexidade" de Edgar Morin (2005). Os propósitos, os objetivos, as metas, os planos não são elaborados antes, mas também a partir da ação. Não há separação entre teoria e prática, subjetividade da objetividade, do pensar e agir, não se planeja a reunião de trabalho, uma vez que os projetos surgem da ação e são modificados através da ação.

Currículos não-disciplinares contrapõem-se ao racionalismo técnico e à divisão e especialização do trabalho docente, uma epistemologia da própria prática, ao agirmos interativamente. Nesse contexto, o "conhecimento na ação", "reflexão na ação", "reflexão sobre a ação", "reflexão sobre a reflexão na ação" são noções fundamentais nesse 
trabalho de construção curricular (SCHÖN, 1998). A reflexão sistemática promove não só a capacidade de investigação sobre a ação, mas também valoriza os saberes gerados nesse processo, mesmos que não possuam "validade" de teoria científica reconhecida e estabelecida, e sim valor pedagógico "formativo", pois são discursos e narrativas que foram construídos na observação e investigação do cotidiano, e o nível de avanço que conseguirmos será inevitavelmente diferente e melhor qualitativamente em relação ao ponto de partida.

Po outro lado, a "dialogicidade freiriana" é fundamental para se evitar que a própria crítica se torne hegemônica e engessada. O educador só pode tornar-se apropriando-se e relacionando-se com o mundo. "É relação de um sujeito com o mundo, com ele mesmo e com os outros. É relação com o mundo como conjunto de significados, mas, também, como espaço e atividades, e se inscreve no tempo" (CHARLOT, 2000, p. 78).

Nessa perspectiva é que dizemos que sem "currículos contemporâneos integrados", "não-disciplinares", a "curricularização" seja da extensão, do ensino ou da pesquisa de forma dissociável, não passará de "acreditação" de disciplinas e atividades desintegradas e desintegradoras do itinerário curricular e da formação docente na atualidade.

\section{REFERÊNCIAS}

BRASIL. Conselho Nacional de Educação. Parecer CNE/CES 608/2018. Diretrizes para as políticas de extensão da educação superior brasileira. Disponível em <http://www.portal.mec.gov.br>. Acesso em: 27 dez. 2020.

BRASIL. Lei $n^{\circ}$ 9394/96, de 20 de dezembro de 1996. Estabelece as diretrizes e bases da Educação Nacional. Disponível em <http://www.planalto.gov.br/ccivil_03/leis/L9394.htm>. Acesso em: 29 dez. 2020.

CHARLOT, B. Da relação com o saber: elementos para uma teoria. Porto Alegre, RS: Artmed, 2000.

DOLL JR., W. E. Currículo: uma perspectiva pós-moderna. Trad. Maria Adriana Veríssimo Veronese. Porto Alegre, RS: Artes Médicas, 1997. 
DUTRA, H.; DAMAS, L. A. H.; ROCHA, D. O currículo como vivência da complexidade no espaço escolar. In: Revista ETD: Educação Temática Digital, v. 11, p. 35, 2009.

FAZENDA, I. C. A. (Org.). O que é interdisciplinaridade? São Paulo, SP: Cortez, 2008.

FAZENDA, I. C. A. Integração como proposta de uma nova ordem na educação. In: CANDAU, V. M. (Org.). Linguagens, espaços e tempos no ensinar e aprender. 2 eds., Rio de Janeiro, RJ: DP\&A, 2001.

FORPROEX. Fórum de Pró-Reitores das Instituições Públicas de Educação Superior Brasileiras. Política Nacional de Extensão Universitária. Manaus. 2012. Disponível em: <https://proex.ufsc.br/files/2016/04/Pol\%C3\%ADtica-Nacionalde-Extens\%C3\%A3o-Universit\%C3\%A 1ria-e-book.pdf>. Acesso em: 31 dez. 2020.

GALLO, S. A orquídea e a vespa: transversalidade e currículo rizomático. In: PEREIRA, M. Z. da C. et al. Currículo e contemporaneidade: questões emergentes. Campinas, SP: Alínea, 2004.

GALLO, S. Disciplinaridade e transversalidade. In: CANDAU, V. M. (Org.). Linguagens, espaços e tempos no ensinar e aprender. 2. ed., Rio de Janeiro, RJ: DP\&A, 2001.

LOPES, A. C. Organização do conhecimento escolar: analisando a disciplinaridade e a integração. In: CANDAU, V. M. (Org.). Linguagens, espaços e tempos no ensinar e aprender. 2. ed., Rio de Janeiro, RJ: DP\&A, 2001, p. 147-183.

MACEDO, R. S. Currículo: campo, conceito e pesquisa. Petrópolis, RJ: 2007.

MACEDO, E. O que significa currículo disciplinar? In: In: CANDAU, V. M. (Org.). Linguagens, espaços e tempos no ensinar e aprender. 2. ed., Rio de Janeiro, RJ: DP\&A, 2001, p. 181- 188.

MIRANDA, J. F. B.; ROCHA, D. Cibercultura e mobilidade: a utilização de smartphones em sala de aula. In: Revista Humanidades \& Inovação, v. 7, p. 104-120, 2020.

MORIN, E. Introdução ao pensamento complexo. 2. ed., Porto Alegre: Sulina, 2005.

MOREIRA, J. M. A. Insterdisciplinaridade: as disciplinas e a interdisciplinaridade brasileira. In: FAZENDA, I. (org.). Que é interdisciplinaridade? São Paulo: Cortez, 2008, p. 85-95. 
PAIVA. C. C. de (org.). Extensão universitária, políticas públicas e desenvolvimento regional. São Paulo, SP: Cultura Acadêmica, 2018.

PNPG. Plano Nacional de Pós-Graduação (PNPG 2011-2020). Documentos setoriais. v. II, Brasília: DF, 2010. Disponível em: <https://www.gov.br/capes/ptbr/centrais-de-conteudo/pnpg-miolo-v2-pdf> Acesso em: 27 dez. 2020.

PPGED/UFPA. Programa de Pós-graduação em Educação da UFPA.

Disponível em: <www.ppged.propesp.ufpa.br> Acesso em: 27 dez. 2020.

PPGED/UEPA. Programa de Pós-graduação em Educação da UEPA.

Disponível em: https://ccse.vepa.br/ppged Acesso em: 27 dez. 2020.

PPGE/UFT. Programa de Pós-graduação em Educação da UFT. Disponível em: https://ww2.uft.edu.br/ppge Acesso em: 27 dez. 2020.

ROCHA, D.; SOARES FILHO, V. UAB na Federal do Tocantins: uma experiência de colaboração, gestão e inovação na educação mediada por tecnologias. In: Revista Observatório, v. 5, p. 1-49, 2019.

ROCHA, D. Relações líquidas, flexíveis, resilientes e Universidade nômade. In: SANTANA, J.; ROCHA, D.; APOLINÁRIO, J.; ROLIM, C. (Orgs.). Resiliências educativas. Goiânia - GO: Editora América, 2013.

SILVA, T. T. da. Documentos de identidade: uma introdução às teorias do currículo. 2. ed. Belo Horizonte, MG: Autêtica, 2000.

SACRISTÁN, J. G. O currículo: uma reflexão sobre a prática. 3. ed. Porto Alegre, RS: Artmed, 2000.

SANTOMÉ, J. T. As culturas negadas e silenciadas no currículo. In: SILVA, T. T. da. Alienígenas na sala de aula: uma introdução aos estudos culturais em educação. Rio de Janeiro, Rio: Vozes, 1995.

SCHÖN, D. Formar professores como profissionais reflexivos. In: NÓVOA, A. Os professores e a sua formação. Lisboa: Dom Quixote, 1992. p. 79-91.

VASCONCELOS, E. M. Complexidade e pesquisa interdisciplinar:

epistemologia e metodologia operativa. 3. ed. Petrópolis, RJ: Vozes. 2007.

Recebido em: 17 de setembro de 2020.

Aprovado em: 28 de março de 2021 .

ado em: 26 de abril de 2021 .

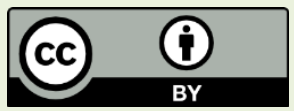

